\title{
Some coupled common fixed points for a pair of mappings in partially ordered G-metric spaces
}

\author{
Sumit Chandok ${ }^{1}$, Wutiphol Sintunavarat ${ }^{2 *}$ and Poom Kumam² ${ }^{*}$
}

\begin{abstract}
The purpose of this paper is to establish some coupled coincidence point theorems for a pair of mappings having a mixed $g$-monotone property in partially ordered $\mathrm{G}$-metric spaces. Also, we present a result on the existence and uniqueness of coupled common fixed points. The results presented in the paper generalize and extend several well-known results in the literature. To illustrate our results, we give some examples.
\end{abstract}

Keywords: Coupled fixed point, Mixed g-monotone property, Ordered G-metric spaces

MSC: $41 \mathrm{~A} 50,47 \mathrm{H} 10,54 \mathrm{H} 25$

\section{Introduction}

Fixed point theory is one of the famous and traditional theories in mathematics and has a large number of applications. The Banach contraction mapping is one of the pivotal results of analysis. It is very popular tool for solving existence problems in many different fields of mathematics. There are a lot of generalizations of the Banach contraction principle in the literature. Ran and Reurings [1] extended the Banach contraction principle in partially ordered sets with some applications to linear and nonlinear matrix equations. While Nieto and RodŕiguezLópez [2] extended the result of Ran and Reurings and applied their main theorems to obtain a unique solution for a first-order ordinary differential equation with periodic boundary conditions. Bhaskar and Lakshmikantham [3] introduced the concept of mixed monotone mappings and obtained some coupled fixed point results. Also, they applied their results on a first-order differential equation with periodic boundary conditions. On the other hand, Mustafa and Sims [4] introduced $G$-metric space which is a generalization of metric spaces in which every triplet of the elements is assigned to a nonnegative real number. Recently, many researchers have

\footnotetext{
${ }^{*}$ Correspondence: poom_teun@hotmail.com; poom.kum@kmutt.ac.th

2 Department of Mathematics, Faculty of Science, King Mongkut's University of Technology Thonburi (KMUTT), Bangkok 10140, Thailand
}

Full list of author information is available at the end of the article obtained fixed point, common fixed point, coupled fixed point and coupled common fixed point results on metric spaces, $G$-metric spaces, partially ordered metric spaces, and partially ordered G-metric spaces (see e.g. [1-3,5-20] and references cited therein). The purpose of this paper is to establish some coupled coincidence point results in partially ordered $G$-metric spaces for a pair of mappings having mixed $g$-monotone property. Also, we present a result on the existence and uniqueness of coupled common fixed points. We supply appropriate examples to make obvious the validity of the propositions of our results.

\section{Preliminaries}

In the sequel, $\mathbb{R}, \mathbb{R}_{+}$, and $\mathbb{N}$ denote the set of real numbers, the set of nonnegative real numbers, and the set of positive integers, respectively.

Definition 2.1. (See [21]). Let $X$ be a non-empty set, and $G: X \times X \times X \rightarrow \mathbb{R}_{+}$be a function satisfying the following properties:

(G1) $G(x, y, z)=0$ if $x=y=z$;

(G2) $0<G(x, x, y)$ for all $x, y \in X$ with $x \neq y$;

(G3) $G(x, x, y) \leq G(x, y, z)$ for all $x, y, z \in X$ with $y \neq z$;

(G4) $G(x, y, z)=G(x, z, y)=G(y, z, x)=\ldots$ (symmetry in all three variables);

\section{是 Springer}

(c) 2013 Chandok et al.; licensee Springer. This is an Open Access article distributed under the terms of the Creative Commons Attribution License (http://creativecommons.org/licenses/by/2.0), which permits unrestricted use, distribution, and reproduction in any medium, provided the original work is properly cited. 
(G5) $G(x, y, z) \leq G(x, a, a)+G(a, y, z)$ for all $x, y, z, a \in X$ (rectangle inequality).

Then, the function $G$ is called a generalized metric, or more specially, a $G$-metric on $X$ and the pair $(X, G)$ is called a $G$-metric space.

It can be easily verified that every $G$-metric on $X$ induces a metric $d_{G}$ on $X$ given by

$$
d_{G}(x, y)=G(x, y, y)+G(y, x, x),
$$

for all $x, y \in X$.

Trivial examples of $G$-metric are as follows:

Example 2.2. Let $(X, d)$ be a metric space. The function $G: X \times X \times X \rightarrow \mathbb{R}_{+}$defined by

$$
G(x, y, z)=\max \{d(x, y), d(y, z), d(z, x)\},
$$

or

$$
G(x, y, z)=d(x, y)+d(y, z)+d(z, x),
$$

for all $x, y, z \in X$, is a $G$-metric on $X$

The concepts of convergence, continuity, completeness, and Cauchy sequence have also been defined in [21].

Definition 2.3. (See [21]). Let $(X, G)$ be a $G$-metric space, and let $\left\{x_{n}\right\}$ be a sequence of points of $X$. We say that $\left\{x_{n}\right\}$ is $G$-convergent to $x \in X$ if $\lim _{(n, m) \rightarrow \infty} G\left(x, x_{n}, x_{m}\right)=0$, that is, for any $\epsilon>0$, there exists $N \in \mathbb{N}$ such that $G\left(x, x_{n}, x_{m}\right)<\epsilon$, for all $n, m \geq N$. We call $x$ the limit of the sequence and write $x_{n} \rightarrow x$ as $n \rightarrow \infty$ or $\lim _{n \rightarrow \infty} x_{n}=x$.

It has been shown in [21] that the G-metric induces a Hausdorff topology, and the convergence described in the above definition is relative to this topology. So, a sequence can converge at the most to one point.

Proposition 2.4. (See [21]). Let $(X, G)$ be a G-metric space. The following are equivalent:

(1) $\left\{x_{n}\right\}$ is G-convergent to $x$.

(2) $G\left(x_{n}, x_{n}, x\right) \rightarrow 0$ as $n \rightarrow+\infty$.

(3) $G\left(x_{n}, x, x\right) \rightarrow 0$ as $n \rightarrow+\infty$.

(4) $G\left(x_{n}, x_{m}, x\right) \rightarrow 0$ as $n, m \rightarrow+\infty$.

Definition 2.5. (See [21]). Let $(X, G)$ be a $G$-metric space. A sequence $\left\{x_{n}\right\}$ is called a G-Cauchy sequence if, for any $\epsilon>0$, there is $N \in \mathbb{N}$ such that $G\left(x_{n}, x_{m}, x_{l}\right)<\epsilon$ for all $m, n, l \geq N$, that is, $G\left(x_{n}, x_{m}, x_{l}\right) \rightarrow 0$ as $n, m, l \rightarrow+\infty$.

Proposition 2.6. (See [4]). Let $(X, G)$ be a G-metric space. Then, the following are equivalent:

(1) the sequence $\left\{x_{n}\right\}$ is G-Cauchy;

(2) for any $\epsilon>0$, there exists $N \in \mathbb{N}$ such that $G\left(x_{n}, x_{m}, x_{m}\right)<\epsilon$, for all $m, n \geq N$.
Proposition 2.7. (See [21]). Let $(X, G)$ be a G-metric space. A mapping $f: X \rightarrow X$ is G-continuous at $x \in X$ if and only if it is G-sequentially continuous at $x$, that is, whenever $\left\{x_{n}\right\}$ is G-convergent to $x,\left\{f\left(x_{n}\right)\right\}$ is G-convergent to $f(x)$.

Proposition 2.8. (See [21]). Let $(X, G)$ be a G-metric space. Then, the function $G(x, y, z)$ is jointly continuous in all three of its variables.

Definition 2.9. (See [21]). A $G$-metric space $(X, G)$ is called $G$-complete if every $G$-Cauchy sequence is $G$-convergent in $(X, G)$.

Definition 2.10. (See [14]). Let $(X, G)$ be a $G$-metric space. A mapping $F: X \times X \rightarrow X$ is said to be continuous if for any two G-convergent sequences, $\left\{x_{n}\right\}$ and $\left\{y_{n}\right\}$ converging to $x$ and $y$, respectively, $\left\{F\left(x_{n}, y_{n}\right)\right\}$ is G-convergent to $F(x, y)$.

Definition 2.11. Let $X$ be a non-empty set and $F: X \times$ $X \rightarrow X$ and $g: X \rightarrow X$. The mappings $F$ and $g$ are said to commute if $F(g x, g y)=g(F(x, y))$ for all $x, y \in X$.

Definition 2.12. Let $(X, \preceq)$ be a partially ordered set, and $F: X \rightarrow X$. The mapping $F$ is said to be non-decreasing if for $x, y \in X, x \preceq y$ implies $F(x) \preceq F(y)$; non-increasing if for $x, y \in X, x \preceq y$ implies $F(x) \succeq F(y)$.

Definition 2.13. Let $(X, \preceq)$ be a partially ordered set, and $F: X \times X \rightarrow X$ and $g: X \rightarrow X$. The mapping $F$ is said to have the mixed $g$-monotone property if $F(x, y)$ is monotone $g$-non-decreasing in $x$ and monotone $g$-non-increasing in $y$, that is, for any $x, y \in X$,

$$
x_{1}, x_{2} \in X, g x_{1} \preceq g x_{2} \Rightarrow F\left(x_{1}, y\right) \preceq F\left(x_{2}, y\right),
$$

and

$$
y_{1}, y_{2} \in X, g y_{1} \preceq g y_{2} \Rightarrow F\left(x, y_{1}\right) \succeq F\left(x, y_{2}\right) .
$$

If $g$ is identity mapping in Definition 2.13, then the mapping $F$ is said to have the mixed monotone property.

Definition 2.14. Let $X$ be a non-empty set. An element $(x, y) \in X \times X$ is called a coupled coincidence point of the mappings $F: X \times X \rightarrow X$ and $g: X \rightarrow X$ if $F(x, y)=g x$ and $F(y, x)=g y$. If $g x=x$ and $g y=y$, then $(x, y) \in X \times X$ is called a coupled common fixed point.

If $g$ is identity mapping in Definition 2.14, then $(x, y) \in$ $X \times X$ is called a coupled fixed point.

\section{Main results}

In this section, we prove some coupled common fixed point theorems in the context of ordered $G$-metric spaces.

Theorem 3.1. Let $(X, \preceq)$ be a partially ordered set, and $G$ be a $G$-metric on $X$ such that $(X, G)$ is a G-metric space. Suppose that $F: X \times X \rightarrow X$ and $g: X \rightarrow X$ are continuous such that $F$ has the mixed g-monotone property 
on $X$ such that there exist two elements $x_{0}, y_{0} \in X$ with $g\left(x_{0}\right) \preceq F\left(x_{0}, y_{0}\right)$ and $g\left(y_{0}\right) \succeq F\left(y_{0}, x_{0}\right)$. Suppose that there exist non-negative real numbers $\alpha, \beta$ and $L$ with $\alpha+\beta<1$ such that

$$
\begin{gathered}
G(F(x, y), F(u, v), F(w, z)) \\
\leq \alpha G(g x, g u, g w)+\beta G(g y, g v, g z)+L \min \{G(F(x, y), \\
g u, g w), G(F(u, v), g x, g w), \\
G(F(w, z), g x, g u), G(F(x, y), g x, g x), G(F(u, v), \\
g u, g u), G(F(w, z), g w, g w)\}
\end{gathered}
$$

for all $x, y, u, v, w, z \in X$ with $g x \succeq g u \geq g w$ and $g y \preceq g v \preceq g z$, either $g u \neq g w$ or $g v \neq g z$. Furthermore, suppose that $F(X \times X) \subseteq g(X), g(X)$ is a G-complete subspace of $X$, and $g$ commutes with $F$, then there exist $x, y \in X$ such that $F(x, y)=g x$ and $g y=F(y, x)$, that is, $F$ and $g$ have a coupled coincidence point $(x, y) \in X \times X$.

Proof. Let $x_{0}, y_{0} \in X$ be such that $g x_{0} \preceq F\left(x_{0}, y_{0}\right)$ and $g y_{0} \succeq F\left(y_{0}, x_{0}\right)$. Since $F(X \times X) \subseteq g(X)$, we can construct sequences $\left\{x_{n}\right\}$ and $\left\{y_{n}\right\}$ in $X$ such that

$$
g x_{n+1}=F\left(x_{n}, y_{n}\right) \text { and } g y_{n+1}=F\left(y_{n}, x_{n}\right), \forall n \geq 0 .
$$

If there exists $n^{\star} \in \mathbb{N}$ such that $g x_{n^{\star}-1}=g x_{n^{\star}}$ and $g y_{n^{\star}-1}=g y_{n^{\star}}$, then $g x_{n^{\star}-1}=F\left(x_{n^{\star}-1}, y_{n^{\star}-1}\right)$ and $g y_{n^{\star}-1}=F\left(y_{n^{\star}-1}, x_{n^{\star}-1}\right)$ that is a point $\left(x_{n^{\star}-1}, y_{n^{\star}-1}\right) \in$ $X \times X$ is a coupled coincidence point of $F$ and $g$. Thus, we may assume that $g x_{n-1} \neq g x_{n}$ or $g y_{n-1} \neq g y_{n}$ for all $n \in \mathbb{N}$.

Next, we claim that for all $n \geq 0$,

$$
g x_{n} \preceq g x_{n+1},
$$

and

$$
g y_{n} \geq g y_{n+1} .
$$

We shall use the mathematical induction. Let $n=0$. Since $g x_{0} \preceq F\left(x_{0}, y_{0}\right)$ and $g y_{0} \succeq F\left(y_{0}, x_{0}\right)$, in view of $g x_{1}=F\left(x_{0}, y_{0}\right)$ and $g y_{1}=F\left(y_{0}, x_{0}\right)$, we have $g x_{0} \preceq g x_{1}$ and $g y_{0} \succeq g y_{1}$, that is, (3.3) and (3.4) hold for $n=0$. Suppose (3.3) and (3.4) hold for some $n \geq 0$. As $F$ has the mixed $g$-monotone property, and $g x_{n} \preceq g x_{n+1}$ and $g y_{n} \succeq g y_{n+1}$, from (3.2), we get

$$
\begin{aligned}
g x_{n+1} & =F\left(x_{n}, y_{n}\right) \preceq F\left(x_{n+1}, y_{n}\right) \preceq F\left(x_{n+1}, y_{n+1}\right) \\
& =g x_{n+2},
\end{aligned}
$$

and

$$
\begin{aligned}
g y_{n+1} & =F\left(y_{n}, x_{n}\right) \succeq F\left(y_{n+1}, x_{n}\right) \succeq F\left(y_{n+1}, x_{n+1}\right) \\
& =g y_{n+2} .
\end{aligned}
$$

Now, from (3.5) and (3.6), we obtain that $g x_{n+1} \preceq g x_{n+2}$ and $g y_{n+1} \succeq g y_{n+2}$. Thus, by the mathematical induction, we conclude that (3.3) and (3.4) hold for all $n \geq 0$. Therefore,

$$
g x_{0} \preceq g x_{1} \preceq g x_{2} \preceq \ldots \preceq g x_{n} \preceq g x_{n+1} \preceq \ldots
$$

and

$$
g y_{0} \succeq g y_{1} \succeq g y_{2} \succeq \ldots \succeq g y_{n} \succeq g y_{n+1} \succeq \ldots .
$$

Since $g x_{n} \succeq g x_{n-1}$ and $g y_{n} \preceq g y_{n-1}$, where $g x_{n} \neq g x_{n-1}$ or $g y_{n} \neq g y_{n-1}$ for all $n \in \mathbb{N}$, from (3.1) and (3.2), we have

$$
\begin{aligned}
& G\left(g x_{n+1}, g x_{n+1}, g x_{n}\right)= G\left(F\left(x_{n}, y_{n}\right), F\left(x_{n}, y_{n}\right), F\left(x_{n-1}, y_{n-1}\right)\right) \\
& \leq \alpha G\left(g x_{n}, g x_{n}, g x_{n-1}\right)+\beta G\left(g y_{n}, g y_{n}, g y_{n-1}\right) \\
&+ L \min \left\{G\left(F\left(x_{n}, y_{n}\right), g x_{n}, g x_{n-1}\right),\right. \\
& G\left(F\left(x_{n}, y_{n}\right), g x_{n}, g x_{n-1}\right), G\left(F\left(x_{n-1}, y_{n-1}\right),\right. \\
&\left.g x_{n}, g x_{n}\right), G\left(F\left(x_{n}, y_{n}\right), g x_{n}, g x_{n}\right), \\
& G\left(F\left(x_{n}, y_{n}\right), g x_{n}, g x_{n}\right), G\left(F\left(x_{n-1}, y_{n-1}\right),\right. \\
&\left.\left.g x_{n-1}, g x_{n-1}\right)\right\}
\end{aligned}
$$

which implies that $G\left(g x_{n+1}, g x_{n+1}, g x_{n}\right) \leq \alpha G\left(g x_{n}, g x_{n}\right.$, $\left.g x_{n-1}\right)+\beta G\left(g y_{n}, g y_{n}, g y_{n-1}\right)$. Similarly, we have $G\left(g y_{n+1}, g y_{n+1}, g y_{n}\right) \leq \alpha G\left(g y_{n}, g y_{n}, g y_{n-1}\right)+\beta G\left(g x_{n}\right.$, $\left.g x_{n}, g x_{n-1}\right)$. Hence, $G\left(g x_{n+1}, g x_{n+1}, g x_{n}\right)+G\left(g y_{n+1}\right.$, $\left.g y_{n+1}, g y_{n}\right) \leq(\alpha+\beta)\left(G\left(g x_{n}, g x_{n}, g x_{n-1}\right)+G\left(g y_{n}, g y_{n}\right.\right.$, $\left.\left.g y_{n-1}\right)\right)$. Set $\left\{\varrho_{n}:=G\left(g x_{n+1}, g x_{n+1}, g x_{n}\right)+G\left(g y_{n+1}, g y_{n+1}\right.\right.$, $\left.\left.g y_{n}\right)\right\}$ and $\delta=\alpha+\beta<1$, we have

$$
0 \leq \varrho_{n} \leq \delta \varrho_{n-1} \leq \delta^{2} \varrho_{n-2} \leq \ldots \leq \delta^{n} \varrho_{0} .
$$

Now, we shall prove that $\left\{g x_{n}\right\}$ and $\left\{g y_{n}\right\}$ are G-Cauchy sequences. For each $m>n$, we have

$$
\begin{aligned}
& G\left(g x_{n}, g x_{m}, g x_{m}\right) \leq G\left(x_{n}, x_{n+1}, x_{n+1}\right) \\
& \quad+G\left(x_{n+1}, x_{n+2}, x_{n+2}\right)+\ldots+G\left(g x_{m-1}, g x_{m}, g x_{m}\right)
\end{aligned}
$$

and

$$
\begin{aligned}
& G\left(g y_{n}, g y_{m}, g y_{m}\right) \leq G\left(y_{n}, y_{n+1}, y_{n+1}\right) \\
& \quad+G\left(y_{n+1}, y_{n+2}, y_{n+2}\right)+\ldots+G\left(g y_{m-1}, g y_{m}, g y_{m}\right) .
\end{aligned}
$$

There fore,

$$
\begin{aligned}
G\left(g x_{n}, g x_{m}, g x_{m}\right)+G\left(g y_{n}, g y_{m}, g y_{m}\right) & \leq \varrho_{n}+\varrho_{n+1}+\ldots+ \\
& \varrho_{m-1} \\
& \left(\delta^{n}+\delta^{n+1}+\ldots+\right. \\
& \left.\delta^{m-1}\right) \varrho_{0} \\
& \leq \frac{\delta^{n}}{1-\delta} \varrho_{0}
\end{aligned}
$$

which implies that $\lim _{m, n \rightarrow \infty}\left[G\left(g x_{n}, g x_{m}, g x_{m}\right)+G\left(g y_{n}\right.\right.$, $\left.\left.g y_{m}, g y_{m}\right)\right]=0$. Therefore, $\left\{g x_{n}\right\}$ and $\left\{g y_{n}\right\}$ are G-Cauchy sequences in $g(X)$. Since $g(X)$ is a $G$-complete subspace of $X$, there is $(x, y) \in X \times X$ such that $\left\{g x_{n}\right\}$ and $\left\{g y_{n}\right\}$ are respectively $G$-convergent to $x$ and $y$.

Using continuity of $g$, we get

$$
\lim _{n \rightarrow \infty} g\left(g x_{n}\right)=g\left(\lim _{n \rightarrow \infty} g x_{n}\right)=g x
$$

and

$$
\lim _{n \rightarrow \infty} g\left(g y_{n}\right)=g\left(\lim _{n \rightarrow \infty} g y_{n}\right)=g y .
$$


Since $g x_{n+1}=F\left(x_{n}, y_{n}\right)$ and $g y_{n+1}=F\left(y_{n}, x_{n}\right)$, hence the commutativity of $F$ and $g$ yields that $F\left(g x_{n}, g y_{n}\right)=g F\left(x_{n}, y_{n}\right)=g\left(g x_{n+1}\right)$ and $F\left(g y_{n}, g x_{n}\right)=$ $g F\left(y_{n}, x_{n}\right)=g\left(g y_{n+1}\right)$.

Now, we show that $F(x, y)=g x$ and $F(y, x)=g y$.

The mapping $F$ is continuous, so since the sequences $\left\{g x_{n}\right\}$ and $\left\{g y_{n}\right\}$ are respectively $G$-convergent to $x$ and $y$; hence, using Definition 2.10, the sequence $\left\{F\left(g x_{n}, g y_{n}\right)\right\}$ is G-convergent to $F(x, y)$. Therefore, $\left\{g\left(g x_{n+1}\right)\right\}$ is G-convergent to $F(x, y)$. By uniqueness of the limit, we have $F(x, y)=g x$. Similarly, we can show that $F(y, x)=g y$. Hence, $(x, y)$ is a coupled coincidence point of $F$ and $g$.

In the next theorem, we replace the continuity of $F$ with the following definition:

Definition 3.2. Let $(X, \preceq)$ be a partially ordered set, and $G$ be a $G$-metric on $X$. We say that $(X, G, \preceq)$ is regular if the following conditions hold:

(1) if a non-decreasing sequence $\left\{x_{n}\right\}$ is such that $x_{n} \rightarrow x$, then $x_{n} \preceq x$ for all $n$,

(2) if a non-increasing sequence $\left\{y_{n}\right\}$ is such that $y_{n} \rightarrow y$, then $y \preceq y_{n}$ for all $n$.

Theorem 3.3. Let $(X, \preceq)$ be a partially ordered set, and $G$ be a $G$-metric on $X$ such that $(X, G, \preceq)$ is regular. Suppose that $F: X \times X \rightarrow X$ and $g: X \rightarrow X$ are self mappings on $X$, such that $F$ has the mixed $g$-monotone property on $X$ such that there exist two elements $x_{0}, y_{0} \in X$ with $g\left(x_{0}\right) \preceq$ $F\left(x_{0}, y_{0}\right)$ and $g\left(y_{0}\right) \succeq F\left(y_{0}, x_{0}\right)$. Suppose that there exist non-negative real numbers $\alpha, \beta$ and $L$ with $\alpha+\beta<1$ such that (3.1) satisfies for all $x, y, u, v, w, z \in X$ with $g x \succeq g u \succeq$ $g w$ and $g y \preceq g v \preceq g z$, where either $g u \neq g w$ or $g v \neq g z$. Further, suppose that $F(X \times X) \subseteq g(X)$, and $(g(X), G)$ is a complete G-metric. Then, there exist $x, y \in X$ such that $F(x, y)=g(x)$ and $g y=F(y, x)$, that is, $F$ and $g$ have $a$ coupled coincidence point $(x, y) \in X \times X$.

Proof. Following the proof of Theorem 3.1, we will get two G-Cauchy sequences $\left\{g x_{n}\right\}$ and $\left\{g y_{n}\right\}$ in the complete $G$-metric space $(g(X), G)$. Then, there exist $x, y \in X$ such that $g x_{n} \rightarrow g x$ and $g y_{n} \rightarrow g y$ as $n \rightarrow \infty$. Since $\left\{g x_{n}\right\}$ is non-decreasing and $\left\{g y_{n}\right\}$ is non-increasing, using the regularity of $(X, G, \preceq)$, we have $g x_{n} \preceq g x$ and $g y \preceq g y_{n}$ for all $n \geq 0$. If $g x_{n^{\star}}=g x$ and $g y_{n^{\star}}=g y$ for some $n^{\star} \geq 0$, then $g x=g x_{n^{\star}} \preceq g x_{n^{\star}+1} \preceq g x=g x_{n^{\star}}$ and $g y \preceq g y_{n^{\star}+1} \preceq$ $g y_{n^{\star}}=g y$, which implies that

$$
g x_{n^{\star}}=g x_{n^{\star}+1}=F\left(x_{n^{\star}}, y_{n^{\star}}\right)
$$

and

$$
g y_{n^{\star}}=g y_{n^{\star}+1}=F\left(y_{n^{\star}}, x_{n^{\star}}\right),
$$

that is, $\left(x_{n^{\star}}, y_{n^{\star}}\right)$ is a coupled coincidence point of $F$ and $g$. Therefore, we suppose that $g x_{n} \neq g x$ or $g y_{n} \neq g y$ for all $n \geq 0$. Using rectangle inequality, commutativity, and (3.1), we have

$$
\begin{aligned}
G\left(g x_{n+1}, g x_{n+1}, F(x, y)\right)= & G\left(F\left(x_{n}, y_{n}\right), F\left(x_{n}, y_{n}\right), F(x, y)\right) \\
\leq & \alpha G\left(g x_{n}, g x_{n}, g x\right)+\beta G\left(g y_{n}, g y_{n}, g y\right) \\
+ & L \min \left\{G\left(g x_{n+1}, g x_{n}, g x\right),\right. \\
& G\left(g x_{n+1}, g x_{n}, g x\right), G\left(F(x, y), g x_{n}, g x_{n}\right), \\
& G\left(g x_{n+1}, g x_{n}, g x\right), \\
& \left.G\left(g x_{n+1}, g x_{n}, g x\right), G(F(x, y), g x, g x)\right\} .
\end{aligned}
$$

Taking $n \rightarrow \infty$, we get $G(g x, g x, F(x, y))=0$ and hence $g x=F(x, y)$. Similarly, one can show that $g y=F(y, x)$. Thus $F$ and $g$ have a coupled coincidence point.

Remark 3.1. A G-metric naturally induces a metric $d_{G}$ given by $d_{G}(x, y)=G(x, y, y)+G(x, x, y)$ [4]. From the condition that either $g u \neq g w$ or $g v \neq g z$, the inequality (3.1) does not reduce to any metric inequality with the metric $d_{G}$. Therefore, the corresponding metric space $\left(X, d_{G}\right)$ results are not applicable to Theorems 3.1 and 3.3.

Taking $L=0$ in Theorems 3.1 and 3.3, we have the following result:

Corollary 3.4. Let $(X, \preceq)$ be a partially ordered set, and $G$ be a G-metric on $X$ such that $(X, G)$ is a G-metric space. Suppose that $F: X \times X \rightarrow X$ and $g: X \rightarrow X$ are continuous self mappings on $X$ such that $F$ has the mixed $g$-monotone property on $X$ such that there exist two elements $x_{0}, y_{0} \in X$ with $g\left(x_{0}\right) \preceq F\left(x_{0}, y_{0}\right)$ and $g\left(y_{0}\right) \succeq F\left(y_{0}, x_{0}\right)$. Suppose that there exist non-negative real numbers $\alpha, \beta$ with $\alpha+\beta<1$ such that

$$
G(F(x, y), F(u, v), F(w, z)) \leq \alpha G(g x, g u, g w)+\beta G(g y, g v, g z),
$$

for all $x, y, u, v, w, z \in X$ with $g x \succeq g u \succeq g w$ and $g y \preceq$ $g v \preceq g z$, where either $g u \neq g w$ or $g v \neq g z$. Further, suppose $F(X \times X) \subseteq g(X), g(X)$ is a G-complete subspace of $X$ and $g$ commutes with $F$. Then, there exist $x, y \in X$ such that $F(x, y)=g x$ and $g y=F(y, x)$, that is, $F$ and $g$ have a coupled coincidence point $(x, y) \in X \times X$.

Corollary 3.5. Let $(X, \preceq)$ be a partially ordered set, and $G$ be a $G$-metric on $X$ such that $(X, G, \preceq)$ is regular. Suppose that $F: X \times X \rightarrow X$ and $g: X \rightarrow X$ are self mappings on $X$ such that $F$ has the mixed $g$-monotone property on $X$ such that there exist two elements $x_{0}, y_{0} \in X$ with $g\left(x_{0}\right) \preceq$ $F\left(x_{0}, y_{0}\right)$ and $g\left(y_{0}\right) \succeq F\left(y_{0}, x_{0}\right)$. Suppose that there exist non-negative real numbers $\alpha, \beta$ with $\alpha+\beta<1$ such that (3.11) satisfies for all $x, y, u, v, w, z \in X$ with $g x \succeq g u \succeq g w$ and $g y \preceq g v \preceq g z$, where either $g u \neq g w$ or $g v \neq g z$. Further, suppose that $F(X \times X) \subseteq g(X)$, and $(g(X), G)$ is a complete $G$-metric, then there exist $x, y \in X$ such that $F(x, y)=g(x)$ and $g y=F(y, x)$, that is, $F$ and $g$ have $a$ coupled coincidence point $(x, y) \in X \times X$. 
Taking $\alpha=\beta=\frac{k}{2}$, where $k \in[0,1)$ and $L=0$ in Theorems 3.1 and 3.3, we have the following result:

Corollary 3.6. Let $(X, \preceq)$ be a partially ordered set, and $G$ be a G-metric on $X$ such that $(X, G)$ is a G-metric space. Suppose that $F: X \times X \rightarrow X$ and $g: X \rightarrow X$ are continuous such that $F$ has the mixed g-monotone property on $X$ such that there exist two elements $x_{0}, y_{0} \in X$ with $g\left(x_{0}\right) \preceq F\left(x_{0}, y_{0}\right)$ and $g\left(y_{0}\right) \succeq F\left(y_{0}, x_{0}\right)$. Suppose that there exists $k \in[0,1)$ such that

$$
G(F(x, y), F(u, v), F(z, w)) \leq \frac{k}{2}(G(g x, g u, g w)+G(g y, g v, g z)),
$$

for all $x, y, u, v, w, z \in X$ with $g x \succeq g u \succeq g w$ and $g y \preceq$ $g v \preceq g z$, where either $g u \neq g w$ or $g v \neq g z$. Further, suppose $F(X \times X) \subseteq g(X), g(X)$ is a G-complete subspace of $X$ and $g$ commutes with $F$, then there exist $x, y \in X$ such that $F(x, y)=g x$ and $g y=F(y, x)$, that is, $F$ and $g$ have a coupled coincidence point $(x, y) \in X \times X$.

Corollary 3.7. Let $(X, \preceq)$ be a partially ordered set, and $G$ be a $G$-metric on $X$ such that $(X, G, \preceq)$ is regular. Suppose that $F: X \times X \rightarrow X$ and $g: X \rightarrow X$ are self mappings on $X$ such that $F$ has the mixed $g$-monotone property on $X$ such that there exist two elements $x_{0}, y_{0} \in X$ with $g\left(x_{0}\right) \preceq$ $F\left(x_{0}, y_{0}\right)$ and $g\left(y_{0}\right) \succeq F\left(y_{0}, x_{0}\right)$. Suppose that there exists $k \in[0,1)$ such that (3.12) satisfies for all $x, y, u, v, w, z \in X$ with $g x \succeq g u \succeq g w$ and $g y \preceq g v \preceq g z$, where either $g u \neq$ $g w$ or $g v \neq g z$. Further, suppose that $F(X \times X) \subseteq g(X)$, and $(g(X), G)$ is a complete $G$-metric. Then, there exist $x, y \in X$ such that $F(x, y)=g(x)$ and $g y=F(y, x)$, that is, $F$ and $g$ have a coupled coincidence point $(x, y) \in X \times X$.

Remark 3.2. Corollaries 3.6 and 3.7 are generalization of the results of Choudhury and Maity [14].

Now, we shall prove the existence and uniqueness of a coupled common fixed point. Note that if $(X, \preceq)$ is a partially ordered set, then we endow the product space $X \times X$ with the following partial order relation:

$$
\text { for }(x, y),(u, v) \in X \times X,(u, v) \preceq(x, y) \Leftrightarrow x \preceq u, y \succeq v \text {. }
$$

Theorem 3.8. In addition to the hypotheses of Theorem 3.1, suppose that for every $(x, y),(z, t) \in X \times X$, there exists $(u, v) \in X \times X$ such that $(F(u, v), F(v, u))$ is comparable to $(F(x, y), F(y, x))$ and $(F(z, t), F(t, z))$. Then, $F$ and g have a unique coupled common fixed point, that is, there exists a unique $(x, y) \in X \times X$ such that $x=g x=F(x, y)$ and $y=g y=F(y, x)$.

Proof. From Theorem 3.1, the set of coupled coincidence points of $F$ and $g$ is non-empty. Suppose that $(x, y)$ and $(z, t)$ are coupled coincidence points of $F$ and $g$, that is, $g x=F(x, y), g y=F(y, x), g z=F(z, t)$, and $g t=F(t, z)$. We shall show that $g x=g z$ and $g y=g t$. By the assumption, there exists $(u, v) \in X \times X$ such that $(F(u, v), F(v, u))$ is comparable with $(F(x, y), F(y, x))$ and $(F(z, t), F(t, z))$. Put $u_{0}=u$ and $v_{0}=v$, and choose $u_{1}, v_{1} \in X$ so that $g u_{1}=F\left(u_{0}, v_{0}\right)$ and $g v_{1}=F\left(v_{0}, u_{0}\right)$. Then, similarly as in the proof of Theorem 3.1, we can inductively define sequences $\left\{g u_{n}\right\}$ and $\left\{g v_{n}\right\}$ as $g u_{n+1}=F\left(u_{n}, v_{n}\right)$ and $g v_{n+1}=F\left(v_{n}, u_{n}\right)$ for all $n$. Further, set $x_{0}=x$, $y_{0}=y, z_{0}=z$, and $t_{0}=t$ and on the same way define the sequences $\left\{g x_{n}\right\}$ and $\left\{g y_{n}\right\}$, and $\left\{g z_{n}\right\}$ and $\left\{g t_{n}\right\}$. Since $(F(x, y), F(y, x))=\left(g x_{1}, g y_{1}\right)=(g x, g y)$ and $(F(u, v), F(v, u))=\left(g u_{1}, g v_{1}\right)$ are comparable, then $g x \succeq$ $g u_{1}$ and $g y \preceq g v_{1}$. Now, we shall show that $(g x, g y)$ and $\left(g u_{n}, g v_{n}\right)$ are comparable, that is, $g x \succeq g u_{n}$ and $g y \preceq g v_{n}$ for all $n$. Suppose that it holds for some $n \geq 0$, then by the mixed $g$-monotone property of $F$, we have $g u_{n+1}=$ $F\left(u_{n}, v_{n}\right) \preceq F(x, y)=g x$ and $g v_{n+1}=F\left(v_{n}, u_{n}\right) \succeq$ $F(y, x)=g y$. Hence, $g x \succeq g u_{n}$ and $g y \preceq g v_{n}$ hold for all $n$. Thus, from (3.1), we have

$$
\begin{gathered}
G\left(g x, g x, g u_{n+1}\right)=G\left(F(x, y), F(x, y), F\left(u_{n}, v_{n}\right)\right) \\
\leq \alpha G\left(g x, g x, g u_{n}\right)+\beta G\left(g y, g y, g v_{n}\right) \\
+L \min \left\{G\left(F(x, y), g x, g u_{n}\right),\right. \\
G\left(F(x, y), g x, g u_{n}\right), \\
G\left(F\left(u_{n}, v_{n}\right), g x, g x\right), \\
G(F(x, y), g x, g x), \\
G(F(x, y), g x, g x), \\
\left.G\left(F\left(u_{n}, v_{n}\right), g u_{n}, g u_{n}\right)\right\}
\end{gathered}
$$

which implies that $G\left(g x, g x, g u_{n+1}\right) \leq \alpha G\left(g x, g x, g u_{n}\right)+$ $\beta G\left(g y, g y, g v_{n}\right)$. Similarly, we can prove that $G(g y, g y$, $\left.g v_{n+1}\right) \leq \alpha G\left(g y, g y, g v_{n}\right)+\beta G\left(g x, g x, g u_{n}\right)$. Hence,

$$
\begin{aligned}
G\left(g x, g x, g u_{n+1}\right)+G\left(g y, g v_{n+1}\right) \leq & (\alpha+\beta)\left[G\left(g x, g x, g u_{n}\right)\right. \\
& \left.+G\left(g y, g y, g v_{n}\right)\right] \\
\leq & (\alpha+\beta)^{2}\left[G\left(g x, g x, g u_{n-1}\right)\right. \\
& \left.+G\left(g y, g y, g v_{n-1}\right)\right] \\
& \cdots \\
\leq & (\alpha+\beta)^{n+1}\left[G\left(g x, g x, g u_{0}\right)\right. \\
& \left.+G\left(g y, g y g v_{0}\right)\right] .
\end{aligned}
$$

On taking limit, $n \rightarrow \infty$, we get

$$
\lim _{n \rightarrow \infty}\left[G\left(g x, g x, g u_{n+1}\right)+G\left(g y, g y, g v_{n+1}\right)\right]=0
$$

Thus, $\lim _{n \rightarrow \infty} G\left(g x, g x, g u_{n+1}\right)=0$ and $\lim _{n \rightarrow \infty}$ $G\left(g y, g y, g v_{n+1}\right)=0$. Similarly, we can prove that $\lim _{n \rightarrow \infty} G\left(g z, g z, g u_{n}\right)=0=\lim _{n \rightarrow \infty} G\left(g t, g t, g v_{n}\right)$. Hence,

$$
g x=g z \text { and } g y=g t .
$$


Since $g x=F(x, y)$ and $g y=F(y, x)$, by the commutativity of $F$ and $g$, we have

$$
\begin{aligned}
g(g(x))=g(F(x, y))=F(g x, g y), \text { and } g(g y) & =g(F(y, x)) \\
& =F(g y, g x) .
\end{aligned}
$$

Denote $g x=p$ and $g y=q$. Then, $g p=F(p, q)$ and $g q=F(q, p)$. Thus, $(p, q)$ is a coupled coincidence point. Then, from (3.15), with $z=p$ and $t=q$, it follows that $g p=g x$ and $g q=g y$, that is, $g p=p$ and $g q=q$. Hence, $p=g p=F(p, q)$ and $q=g q=F(q, p)$. Therefore, $(p, q)$ is a coupled common fixed point of $F$ and $g$. To prove the uniqueness, assume that $(r, s)$ is another coupled common fixed point. Then, by (3.15), we have $r=g r=g p=p$ and $s=g s=g q=q$. Hence, we get the result.

Finally, we provide some examples to illustrate our obtained Theorem 3.1.

Example 3.9. Let $X=\mathbb{R}$ be a set endowed with order $x \preceq y \Leftrightarrow x \leq y$. Let the mapping $G: X \times X \times X \rightarrow \mathbb{R}_{+}$be defined by

$$
G(x, y, z)=|x-y|+|y-z|+|z-x|,
$$

for all $x, y, z \in X$. Then, $G$ is a $G$-metric on $X$. Define the mapping $F: X \times X \rightarrow X$ and $g: X \rightarrow X$ by

$$
F(x, y)=\frac{x-2 y}{8} \text { for all }(x, y) \in X \times X
$$

and

$$
g x=\frac{x}{2} \text { for all } x \in X .
$$

Then, the following properties hold:

(1) $F$ and $g$ are continuous;

(2) $F$ has a mixed $g$-monotone property;

(3) there exist $x_{0}, y_{0} \in X$ with $g\left(x_{0}\right) \preceq F\left(x_{0}, y_{0}\right)$ and $g\left(y_{0}\right) \succeq F\left(y_{0}, x_{0}\right)$

(4) $F$ satisfies condition (3.1). Indeed, we show that $F$ satisfies condition (3.1).
For all $x, y, u, v, w, z \in X$, we have

$$
\begin{aligned}
& G(F(x, y), F(u, v), F(w, z)) \\
= & \left|\frac{x-2 y}{8}-\frac{u-2 v}{8}\right|+\left|\frac{u-2 v}{8}-\frac{w-2 z}{8}\right| \\
& +\left|\frac{w-2 z}{8}-\frac{x-2 y}{8}\right| \\
\leq & \frac{1}{4}\left(\left|\frac{x}{2}-\frac{u}{2}\right|+\left|\frac{u}{2}-\frac{w}{2}\right|+\left|\frac{w}{2}-\frac{x}{2}\right|\right) \\
+ & \frac{2}{4}\left(\left|\frac{y}{2}-\frac{v}{2}\right|+\left|\frac{v}{2}-\frac{z}{2}\right|+\left|\frac{z}{2}-\frac{y}{2}\right|\right) \\
= & \frac{1}{4} G(g x, g u, g w)+\frac{1}{2} G(g y, g v, g z) \\
\leq & \frac{1}{4} G(g x, g u, g w)+\frac{1}{2} G(g y, g v, g z) \\
+ & L \min \{G(F(x, y), g u, g w), G(F(u, v), g x, g w), \\
& G(F(w, z), g x, g u), G(F(x, y), g x, g x), \\
& G(F(u, v), g u, g u), G(F(w, z), g w, g w)\}
\end{aligned}
$$

for all $L \geq 0$. Hence, $F$ satisfies condition (3.1) for $\alpha=\frac{1}{4}, \beta=\frac{1}{2}$ and for each $L \geq 0$.

(5) $F(X \times X) \subseteq g(X)$ and $g(X)$ is a $G$-complete subspace of $X$;

(6) $F$ and $g$ are commutes. Indeed, we have

$$
F(g x, g y)=F\left(\frac{x}{2}, \frac{y}{2}\right)=\frac{\frac{x}{2}-y}{8}=\frac{\frac{x-2 y}{8}}{2}=g(F(x, y))
$$

for all $x, y \in X$.

Therefore, all hypotheses of Theorem 3.1 hold, and so $F$ and $g$ have a coupled coincidence point that is a point $(0,0) \in X \times X$. Moreover, this point is also coupled common fixed point of $F$ and $g$.

\section{Competing interests}

The authors declare that they have no competing interests.

\section{Authors' contributions}

SC, WS, and PK contributed equally and significantly in writing this paper. All authors read and approved the final manuscript.

\section{Acknowledgements}

The second author would like to thank the Research Professional Development Project under the Science Achievement Scholarship of Thailand (SAST). The third author was supported by the Higher Education Research Promotion and National Research University Project of Thailand, Office of the Higher

Education Commission, for the financial support during the preparation of this paper.

\section{Author details \\ ${ }^{1}$ Department of Mathematics, Khalsa College of Engineering \& Technology (Punjab Technical University), Ranjit Avenue, Amritsar 143001, India. \\ ${ }^{2}$ Department of Mathematics, Faculty of Science, King Mongkut's University of Technology Thonburi (KMUTT), Bangkok 10140, Thailand.}

Received: 20 March 2013 Accepted: 18 April 2013

Published: 10 May 2013

\section{References}

1. Ran, ACM, Reurings, MCB: A fixed point theorem in partially ordered sets and some applications to matrix equations. Proc. Amer. Math. Soc. 132(5), 1435-1443 (2004) 
2. Nieto, JJ, Rodŕiguez-López, R: Contractive mapping theorems in partially ordered sets and applications to ordinary differential equations. Order. 22, 223-239 (2005)

3. Bhaskar, TG, Lakshmikantham, V: Fixed point theorems in partially ordered metric spaces and applications. Nonlinear Anal. 65, 1379-1393 (2006)

4. Mustafa, Z, Sims, B: Some remarks concerning D-metric spaces. Paper presented at the international conference on fixed point theory and applications, Valencia Spain, 13-19 July 2004

5. Agarwal, RP, El-Gebeily, MA, O'Regan, D: Generalized contractions in partially ordered metric spaces. Appl. Anal. 87, 1-8 (2008)

6. Chandok, $\mathrm{S}$ : Some common fixed point theorems for generalized $f$-weakly contractive mappings. J. Appl. Math. Informatics. 29, 257-265 (2011)

7. Chandok, S: Some common fixed point theorems for generalized nonlinear contractive mappings. Comput Math. Appl. 62, 3692-3699 (2011)

8. Chandok, S: Common fixed points, invariant approximation and generalized weak contractions. Internat. J. Math. Math. Sci. 2012. Article ID 102980 (2012). doi:10.1155/2012/102980

9. Chandok, S, Kim, JK: Fixed point theorem in ordered metric spaces for generalized contractions mappings satisfying rational type expressions. J. Nonlinear Funct. Anal. Appl. 17, 301-306 (2012)

10. Chandok, S: Some common fixed point results for generalized weak contractive mappings in partially ordered metric spaces. J. Nonlinear Anal. Optimization (2013, in press)

11. Chandok, S: Common fixed points for generalized nonlinear contractive mappings in metric spaces. Mat. Vesnik. 65(1), 29-34 (2013)

12. Chandokm, S, Khan, MS, Rao, KPR: Some coupled common fixed point theorems for a pair of mappings satisfying a contractive condition of rational type. J. Nonlinear Anal. Appl. (2013). doi:10.5899/2013/jnaa-00174

13. Chandok, S, Khan, MS, Rao, KPR: Some coupled common fixed point theorems for a pair of mappings satisfying a contractive condition of rational type without monotonicity. Internat. J. Math. Anal. 7(9), 433-440 (2013)

14. Choudhury, BS, Maity, P: Coupled fixed point results in generalized metric spaces. Math. Comput. Modell. 54, 73-79 (2011)

15. Lakshmikantham, V, Ciric, L: Coupled fixed point theorems for nonlinear contractions in partially ordered metric spaces. Nonlinear Anl. 70, 4341-4349 (2009)

16. Mustafa, Z, Obiedat, H, Awawdeh, F: Some of fixed point theorem for mapping on complete G-metric spaces. Fixed Point Theory Appl. 2008. Article ID 189870. (2008). doi:10.1155/2008/189870

17. Mustafa, Z, Sims, B: Fixed point theorems for contractive mappings in complete G-metric spaces. Fixed Point Theory Appl. 2009. Article ID 917175 (2009). doi:10.1155/2009/917175

18. Mustafa, Z, Shatanawi, W, Bataineh, M: Existence of fixed point results in G-metric spaces. Int. J. Math. Math. Sci. 2009. Article ID 283028 (2009). doi:10.1155/2009/283028

19. Luong, NV, Thuan, NX: Coupled fixed point theorems in partially ordered metric spaces. Bull. Math. Anal. Appl. 2, 16-24 (2010)

20. Abbas, M, Cho, YJ, Nazir, T: Common fixed points of Ciric-type contractive mappings in two ordered generalized metric spaces. Fixed Point Theory Appl. 2012, 139 (2012)

21. Mustafa, Z, Sims, B: A new approach to generalized metric spaces. J. Nonlinear Convex Anal. 7(2), 289-297 (2006)

\section{doi:10.1186/2251-7456-7-24}

Cite this article as: Chandok et al: Some coupled common fixed points for a pair of mappings in partially ordered $G$-metric spaces. Mathematical Sciences 2013 7:24. 